\title{
High levels of carcinoembryonic antigen and smoking might be markers of colorectal adenoma in Korean males aged 40-49 years
}

In Cheol Yoon, Jeong Hyeon Cho, Heejin Choi, Young Hoon Choi, kyu Min Lim, Sung Hwa Choi, Jae Ho Han, Hyeon Ju Jeong, Hong Sub Lee

\author{
Department of Internal Medicine, Myongji Hospital, Seonam University College of Medicine, Goyang, Korea
}

Background: Prevalence of adenoma in males aged 40-49 years in Korea was higher than expected. The aim of this study was to investigate the prevalence and risk factors of colorectal adenoma in males aged 40-49 years.

Methods: Total 1,902 asymptomatic subjects with a mean age of $47.9 \pm 6.7$ years, who underwent a screening colonoscopy in a health promotion center of Myongji Hospital from 2010 to 2013 were enrolled in this study. We conducted a case-control study to determine the risk factors for adenoma. The subjects were classified into two groups (adenoma vs. controls). To validate the diagnostic value of carcinoembryonic antigen (CEA) for adenoma, area under the receiver operating characteristic curve (AUROC) was calculated.

Results: At least one colorectal adenoma was identified in 385 subjects (20.2\%). Among these 385 subjects, 372 subjects were found to have a non-advanced adenoma, 13 subjects had an invasive adenoma. One subject had cancer. Male sex, age, smoking, metabolic syndrome, and elevated CEA level were significantly associated with a colorectal adenoma in univariate analysis. However, metabolic syndrome was not significant in multivariate analysis. In the male group, the AUROC of CEA for colorectal adenoma was 0.600 ( 0.543 to $0.656)$ in non-smokers under 50 years of age, and $0.615(0.540$ to 0.690$)$ in smokers under 50 years of age. Conclusion: Male sex, smoking, and high levels of CEA seem to be associated with colorectal adenoma. High levels of CEA and smoking may be diagnostic markers for any colorectal adenoma in Korean males aged $40-49$ years.

Keywords: Carcinoembryonic antigen; Colorectal adenoma; Colonoscopy; Risk factors; Smoking

\section{INTRODUCTION}

Colorectal cancer (CRC) incidence is rapidly increasing in many Asian countries, with rates approaching those of Western countries [1]. In South Korea, CRC was the 3rd most commonly diagnosed cancer in 2011, and the incidence of CRC has continued to increase in Korea, with a higher increase in men compared with women [2]. CRC screening is recommended for average-risk persons beginning at age 50 accor-

Received: November 20, 2015, Revised: March 15, 2016 Accepted: March 16, 2015

Corresponding Author: Hong Sub Lee, Department of Internal Medicine, Myongji Hospital, Seonam University College of Medicine, 55 Hwasu-ro 14beon-gil, Deogyang-gu, Goyang 10475, Korea

Tel: +82-31-810-5335, Fax: +82-31-969-0500

E-mail: epoch0123@naver.com ding to the guidelines of many professional societies [3-5]. The most reliable method for early detection of precancerous lesions among the CRC screening methods is colonoscopy which is associated with reduced CRC mortality [6].

Recently, it was reported that the prevalence of overall colorectal neoplasia in men aged 30-39 years exhibiting all risk factors was not lower than that in average-risk women aged $>50$ years [7]. In another study, the authors recommended earlier colorectal screening before 50 years in males with metabolic syndrome and history of smoking [8]. However, it was reported that the prevalence of adenomas was similar between individuals aged 40-49 years and those aged 50-59 years, although the prevalence of advanced neoplasia in the 50-59 years age group may be higher than that in the 40-49 years age group [9]. Also, colonoscopic detection of CRC is uncommon in asymptomatic persons $40-49$ years of 
age [10]. In Korea, although the prevalence of non-advanced adenoma in males aged 40-49 years is higher than that in Western countries, the prevalence of advanced adenoma and adenocarcinoma is lower [11,12]. Although gender, smoking, and metabolic syndrome are important risk factors of colorectal neoplasm, the benefits of earlier screening colonoscopy in subjects with these risk factors remain unclear.

Therefore, the aim of the present study was to investigate the prevalence and risk factors of colorectal adenoma in males aged 40-49 years.

\section{MATERIALS AND METHODS}

\section{Study population}

The study population consisted of subjects who had undergone general check-ups at the health promotion center of Myongii Hospital, Goyang, Korea from January 2010 until December 2013 ( $\mathrm{n}=29,310)$. We excluded subjects with the following characteristics: age under 40 years $(n=9,124)$, subjects who did not receive a colonoscopy $(n=5,467)$, subjects who received a colonoscopy more than 2 times $(n=11,724)$, subjects who were not Korean $(\mathrm{n}=439)$, and subjects who had an incomplete colonoscopy result $(\mathrm{n}=133)$. Total $1,902 \mathrm{sub-}$ jects who underwent first colonoscopy were included in the final analysis (Fig. 1).

The general check-ups included physical examination (including anthropometric measurement, body composition ana-

\begin{tabular}{|c|c|}
\hline $\begin{array}{l}\text { Asymptomatic participants } \\
\text { undergoing routine health } \\
\text { check-up examinations } \\
(n=29,310)\end{array}$ & \\
\hline & $\begin{array}{l}\text { Excluded for one or more of the } \\
\text { following reasons }(n=27,408) \\
>\text { Age }<40(n=9,124) \\
>\text { Lack of colonoscopies }(n=5,467) \\
>\text { Repeated study }(n=11,724) \\
>\text { History of colorectal disease }(n=520) \\
>\text { Foreigner }(n=439) \\
>\text { Incomplete colonoscopies }(n=133) \\
>\text { Colorectal cancer }(n=1)\end{array}$ \\
\hline
\end{tabular}

Included in the analysis $(n=1,902)$

Fig. 1. Flow diagram for selection of study participants. Asymptomatic participants undergoing routine health check-up examinations from January 2010 until December 2013 at Myongi Hospital, Goyang, Korea $(n=29,310)$. lysis, blood pressure), blood tests including metabolic profiles and tumor markers, such as carcinoembryonic antigen (CEA), esophagogastroduodenoscopy, abdominal sonography, plain chest radiography, and electrocardiography. An examinee could select additional screening tests, such as colonoscopy, computed tomography, and so on.

This study was approved by the institutional review board of the Myongji Hospital.

\section{Data collection and definitions}

All examinees were instructed to complete a self-administered health questionnaire before the health check-up. The questionnaire included past history of colorectal disease, drug history, family history of CRC, the amount of alcohol consumption, smoking status, and whether regular exercise was performed or not, and so on. If subjects had undergone two or more colonoscopies during the study period, result of the first colonoscopy was considered in the analysis. Heavy alcohol consumption was defined as drinking $>80 \mathrm{~g}$ of alcohol per day. Smoking status was divided into three categories: (non-smoker, $<20$ pack years, $\geq 20$ pack years)

The percentage of total body mass was calculated by body composition analysis (Inbody 720, BiospaceCo.Ltd., Seoul, South Korea). Arterial stiffness checked in the carotid artery was stratified into two stages (normal vs. abnormal) by pulse wave velocity (PWV) determined with an automatic device (Nippon Colin, Komaki, Japan). Body mass index was calculated as weight $(\mathrm{kg})$ divided by height squared $\left(\mathrm{m}^{2}\right)$.

Metabolic syndrome was diagnosed if three or more of the following five factors were satisfied [13]: (1) high blood pressure or use of antihypertensive drugs, (2) elevated triglycerides $\geq 150 \mathrm{mg} / \mathrm{dL}$ or use of drugs for elevated triglycerides, (3) reduced high-density lipoprotein cholesterol level $(<40 \mathrm{mg} / \mathrm{dL}$ in males, $<50 \mathrm{mg} / \mathrm{dL}$ in females), (4) elevated fasting glucose or use of anti-diabetic medication, and (5) central obesity defined for the Korean population as a waist circumference of $\geq 90 \mathrm{~cm}$ for males and $\geq 85 \mathrm{~cm}$ for females [14].

Colonoscopies were performed by experienced gastroenterologists after bowel preparation with $4 \mathrm{~L}$ of polyethylene glycol solution (Colyte, Taejun, Seoul, South Korea). Advanced adenoma was defined as adenomas with a diameter $\geq 10 \mathrm{~mm}$, and/or with villous component $\geq 25 \%$, and/or with high grade dysplasia. 


\section{Statistical analysis}

Data was divided into two groups (no adenoma vs. any adenoma). Continuous variables were compared using Student's t-test. All continuous variables are expressed as means \pm S.E.M for each group. Categorical variables between the two groups were compared using the Pearson's chi-squared test. For each variable, the odds ratio and 95\% confidence interval were reported. The receiver operating characteristic curve (ROC curve) through logistic regression was calculated to obtain the cut-off value according to smoking status. $p$-values $<0.05$ were considered statistically significant. SPSS for Windows version 11 (SPSS Inc., Chicago, IL, USA) was used for all analyses.

\section{RESULTS}

\section{Prevalence of colorectal adenoma in the study population}

The study included 1,902 asymptomatic subjects who underwent health check-ups in a single endoscopy unit via screening colonoscopy (Fig. 1). Also, 1,391 (males:females= 967:424) subjects were 40-49 years of age, and 511 (males: females $=363: 148$ ) subjects were older than 49 years. Table 1 show the prevalence of colorectal adenoma in the study population. At least one colorectal adenoma was identified in 385 patients (20.2\%). The prevalence of colorectal adenoma was $23.3 \%$ in the male group (311 out of 1,330), and $12.9 \%$ in the female group (74 out of 572). The prevalence of colorectal adenoma in subjects 40-49 years of age and in those $\geq 50$ years was $18.4 \%$ (256 out of 1,391) and 21.2\% (129 out of 511), respectively. Among the subjects with one or more colorectal neoplasms, 372 subjects were found to have a nonadvanced adenoma, 13 subjects had an invasive adenoma. One patient had a cancer.

Table 1. Prevalence of colorectal adenoma in the study population

\begin{tabular}{|c|c|c|c|}
\hline & No adenoma & \multicolumn{2}{|c|}{ Adenoma } \\
\hline \multicolumn{4}{|l|}{ Age } \\
\hline $40-49 \mathrm{yr}$ & 1,135 (82.6) & \multicolumn{2}{|c|}{256 (18.4) } \\
\hline$>49 \mathrm{yr}$ & $382(78.8)$ & \multicolumn{2}{|c|}{$129(21.2)$} \\
\hline \multicolumn{4}{|l|}{ Sex } \\
\hline Male & 1,019 (76.7) & \multicolumn{2}{|c|}{311 (23.3) } \\
\hline \multirow[t]{2}{*}{ Female } & 498 (87.1) & \multicolumn{2}{|c|}{74 (12.9) } \\
\hline & & $\begin{array}{c}\text { Non-advanced } \\
372\end{array}$ & $\begin{array}{c}\text { Advanced } \\
13\end{array}$ \\
\hline
\end{tabular}

Values are presented as number (\%).
Advanced adenoma $(\mathrm{n}=13)$ and colorectal adenocarcinoma $(n=1)$ were found only in male subjects. Seven out of 13 subjects with advanced adenoma belong to male group 40-49 years of age $(0.7 \%, 7$ out of 967$)$.

\section{Risk factors of colorectal adenoma in the study population}

Table 2 and 3 show the differences in demographics and clinical characteristics between the subjects with adenomatous polyps and controls. Male sex, smoking status, existence of metabolic syndrome, and arterial stiffness were significantly associated with colorectal adenoma in univariate analysis. The prevalence of overall colorectal adenoma increase as age, soft lean mass, systolic blood pressure, diastolic blood pressure, glycosylated hemoglobin ( $\mathrm{HbA1c}$ ), abdominal circumference, CEA level, and prostate specific antigen (PSA) level increased.

\section{Risk analysis for colorectal adenoma by gender}

The risk factors for colorectal adenoma in both genders are showed in Table 4 and 5. Age was significantly associated with colorectal adenoma regardless of gender. Arterial stiffness and CEA were significantly associated with colorectal adenoma in male subjects, but a similar effect was not seen in female subjects. PSA was significantly associated with colorectal adenoma in the male group. Smoking ( $\geq 20$ pack years) and $\mathrm{HbA1c}$ tended to be associated with colorectal adenoma in the male group. In the female group, abdominal circumference was significantly associated with colorectal adenoma, but not in the male group.

According to multiple logistic regression, adenoma was significantly associated with male sex, age, smoking, and CEA level (Table 6).

To validate the values of CEA for adenoma, area under the ROC curve (AUROC) was calculated (Table 7). AUROC of CEA for colorectal adenoma in non-smoking male subjects $(\mathrm{n}=585)$ under 50 years of age was 0.600 (95\% CI, 0.5430.656). AUROC of CEA for colorectal adenoma in smoking male subjects $(\mathrm{n}=376)$ under 50 years of age was $0.615(95 \%$ CI, 0.540-0.690). The cut off value of high CEA level was $2.5 \mathrm{ng} / \mathrm{mL}$ in smokers and $1.0 \mathrm{ng} / \mathrm{mL}$ in non-smokers. The sensitivity and specificity of CEA level was $70.9 \%$ and $57.9 \%$ in smokers, and $76.8 \%$ and $64.8 \%$ in non-smokers. 
Table 2. Characteristics of study participants by colorectal adenoma status (categorical variables)

\begin{tabular}{|c|c|c|c|c|c|c|c|}
\hline Characteristic $^{\text {a) }}$ & $\begin{array}{c}\text { Overall } \\
(\mathrm{n}=1,902)\end{array}$ & $\begin{array}{c}\text { No colorectal } \\
\text { adenoma } \\
(n=1,517)\end{array}$ & $\begin{array}{l}\text { Any colorectal } \\
\text { adenoma } \\
(\mathrm{n}=385)\end{array}$ & $\begin{array}{c}\text { Non-advanced } \\
\text { colorectal } \\
\text { adenoma } \\
(\mathrm{n}=372) \\
\end{array}$ & $\begin{array}{c}\text { Advanced } \\
\text { colorectal } \\
\text { adenoma } \\
(\mathrm{n}=13)\end{array}$ & $\begin{array}{l}\text { Adjusted OR } \\
\quad(95 \% \mathrm{CI})\end{array}$ & $p$-values \\
\hline Male & $1,330(69.9)$ & $1,019(67.2)$ & $311(80.8)$ & $298(80.1)$ & $13(100)$ & $2.0(1.5-2.7)$ & $<0.001$ \\
\hline Alcohol consumer $(n=1,897)$ & $919(48.4)$ & $739(48.8)$ & $180(46.9)$ & $172(46.4)$ & $8(61.5)$ & $0.9(0.7-1.1)$ & 0.491 \\
\hline $\begin{array}{l}\text { Smoking ( } \geq 20 \text { pack-years) } \\
\text { (vs never) }(\mathrm{n}=1,902)\end{array}$ & $461(24.2)$ & $351(23.1)$ & $110(28.5)$ & $107(35.0)$ & $3(23.0)$ & $1.3(1.0-1.7)$ & 0.028 \\
\hline $\begin{array}{l}\text { History of hypertension } \\
(\mathrm{n}=1,901)\end{array}$ & $511(26.9)$ & $403(26.6)$ & $108(28.1)$ & $101(27.2)$ & $7(53.8)$ & $1.0(0.8-1.3)$ & 0.562 \\
\hline History of diabetes $(n=1,901)$ & $167(8.8)$ & $133(8.8)$ & $34(8.8)$ & $33(8.9)$ & $1(7.7)$ & $1.0(0.6-1.4)$ & 1.000 \\
\hline $\begin{array}{l}\text { History of dyslipidemia } \\
(\mathrm{n}=1,901)\end{array}$ & $159(8.4)$ & $130(8.6)$ & $29(7.5)$ & $28(7.5)$ & $1(7.7)$ & $0.8(0.5-1.3)$ & 0.606 \\
\hline History of CVA $(n=1,901)$ & $21(1.1)$ & $16(1.1)$ & $5(1.3)$ & $5(1.3)$ & $0(0)$ & $1.2(0.4-3.3)$ & 0.596 \\
\hline $\begin{array}{l}\text { History of angina or myocardial } \\
\text { infarction }(n=1,901)\end{array}$ & $78(4.1)$ & $63(4.2)$ & $15(3.9)$ & $15(4.0)$ & $0(0)$ & $0.9(0.5-1.6)$ & 0.887 \\
\hline Regular exercise $(n=1,897)$ & $1,582(83.4)$ & $1,264(83.5)$ & $318(82.8)$ & $308(83.0)$ & $10(76.9)$ & $0.9(0.7-1.2)$ & 0.759 \\
\hline Metabolic syndrome $(n=1,902)$ & 407 (21.4) & $307(20.2)$ & $100(26.0)$ & $95(25.5)$ & $5(38.5)$ & $1.3(1.0-1.7)$ & 0.018 \\
\hline Stool OB $(n=638)$ & $161(25.2)$ & $133(25.3)$ & $28(24.8)$ & $27(24.5)$ & $1(33.3)$ & $0.9(0.6-1.5)$ & 1.000 \\
\hline Arterial stiffness $(n=723)$ & $303(41.9)$ & $220(39.3)$ & $83(50.9)$ & $81(50.6)$ & $2(66.6)$ & $1.6(1.1-2.2)$ & 0.009 \\
\hline
\end{tabular}

Values are presented as number (\%).

a) All participants had data on age, sex. The number in parentheses in this column indicate the number of participants with data available for each of the variables.

OR, odds ratio; CI, confidence interval; CVA, cerebral vascular accident; Stool OB, stool occult blood.

Table 3. Characteristics of study participants by colorectal adenoma status (continuous variables)

\begin{tabular}{|c|c|c|c|c|c|c|}
\hline Characteristic $^{\text {a) }}$ & $\begin{array}{c}\text { Overall } \\
(\mathrm{n}=1,902)\end{array}$ & $\begin{array}{c}\text { No colorectal } \\
\text { adenoma } \\
(n=1,517) \\
\end{array}$ & $\begin{array}{l}\text { Any colorectal } \\
\text { adenoma } \\
(\mathrm{n}=385) \\
\end{array}$ & $\begin{array}{c}\text { Non-advanced } \\
\text { colorectal adenoma } \\
(\mathrm{n}=372)\end{array}$ & $\begin{array}{c}\text { Advanced } \\
\text { colorectal adenoma } \\
(\mathrm{n}=13)\end{array}$ & \\
\hline Age (yr) & $47.9 \pm 6.7$ & $47.5 \pm 6.6$ & $49.2 \pm 6.7$ & $49.1 \pm 6.6$ & $52.3 \pm 10.2$ & $<0.001$ \\
\hline Soft lean mass $(\mathrm{kg})(\mathrm{n}=1,184)$ & $47.5 \pm 8.9$ & $47.2 \pm 9.1$ & $48.8 \pm 8.0$ & $48.8 \pm 8.1$ & $50.7 \pm 3.7$ & 0.005 \\
\hline Systolic BP (mmHg) $(\mathrm{n}=1,750)$ & $120.7 \pm 12.8$ & $120.2 \pm 12.9$ & $122.5 \pm 12.3$ & $122.5 \pm 12.1$ & $124 \pm 16.0$ & 0.003 \\
\hline Diastolic BP $(\mathrm{mmHg})(\mathrm{n}=1,750)$ & $74.7 \pm 10.0$ & $74.3 \pm 10.1$ & $76.2 \pm 9.7$ & $76.3 \pm 9.7$ & $74.2 \pm 10.4$ & $<0.001$ \\
\hline $\mathrm{HbA1c}(\mathrm{mmol} / \mathrm{mol})(\mathrm{n}=1,364)$ & $5.7 \pm 0.8$ & $5.6 \pm 0.8$ & $5.8 \pm 1.1$ & $5.8 \pm 1.1$ & $5.9 \pm 0.9$ & 0.022 \\
\hline Abdominal circumference $(\mathrm{cm})(\mathrm{n}=1,597)$ & $80.9 \pm 9.0$ & $80.6 \pm 9.2$ & $82.2 \pm 8.1$ & $82.0 \pm 8.0$ & $86.3 \pm 9.9$ & 0.002 \\
\hline Triglycerides (mg/dL) $(\mathrm{n}=1,891)$ & $141.2 \pm 98.8$ & $139 \pm 97.2$ & $149.7 \pm 104.0$ & $147.8 \pm 102.0$ & $205.0 \pm 131.0$ & 0.057 \\
\hline Glucose (mg/dL) (n=1,741) & $82.9 \pm 36.0$ & $82.1 \pm 35.0$ & $86.0 \pm 38.0$ & $86.0 \pm 38.0$ & $88.3 \pm 42.6$ & 0.072 \\
\hline $\mathrm{HDL}(\mathrm{mg} / \mathrm{dL})(\mathrm{n}=1,499)$ & $48.2 \pm 11.2$ & $48.3 \pm 11.2$ & $47.7 \pm 11.0$ & $47.7 \pm 11.1$ & $48.5 \pm 5.4$ & 0.450 \\
\hline CEA (ng/mL) $(n=1,881)$ & $1.4 \pm 1.0$ & $1.3 \pm 1.0$ & $1.6 \pm 1.3$ & $1.6 \pm 1.3$ & $1.3 \pm 0.7$ & $<0.001$ \\
\hline NSE (ng/mL) $(n=278)$ & $6.7 \pm 2.7$ & $6.8 \pm 2.8$ & $6.2 \pm 2.3$ & $6.3 \pm 2.4$ & $5.5 \pm 0.8$ & 0.211 \\
\hline CA19-9 (ng/mL) $(\mathrm{n}=1,453)$ & $8.4 \pm 7.9$ & $8.3 \pm 7.6$ & $8.6 \pm 8.8$ & $8.7 \pm 8.9$ & $6.1 \pm 4.3$ & 0.554 \\
\hline CA125 (ng/mL) $(\mathrm{n}=446)$ & $16.4 \pm 21$ & $16.5 \pm 22.3$ & $15.2 \pm 10.3$ & $15.2 \pm 10.3$ & 0 & 0.657 \\
\hline PSA (ng/mL) $(n=1,279)$ & $1.0 \pm 0.9$ & $1.0 \pm 0.7$ & $1.2 \pm 1.3$ & $1.2 \pm 1.3$ & $0.9 \pm 0.3$ & 0.034 \\
\hline $\operatorname{AFP}(n g / m L)(n=1,478)$ & $3.1 \pm 1.9$ & $3.1 \pm 2.0$ & $3.3 \pm 1.9$ & $3.3 \pm 1.9$ & $3.4 \pm 1.7$ & 0.214 \\
\hline CRP (mg/L) $(n=1,194)$ & $0.2 \pm 1.0$ & $0.2 \pm 0.9$ & $0.3 \pm 1.4$ & $0.3 \pm 1.4$ & $0.1 \pm 0.1$ & 0.306 \\
\hline
\end{tabular}

Values are presented as mean \pm standard deviation.

a) All participants had data on age, sex. The number in parentheses in this column indicate the number of participants with data available for each of the variables.

BP, blood pressure; HbA1c, glycosylated hemoglobin; HDL, high-density lipoprotein; CEA, carcinoembryonic antigen; NSE, neuronspecific enolase; CA19-9, carbohydrate antigen 19-9; CA125, cancer antigen 125; PSA, prostate-specific antigen; AFP, alpha-fetoprotein; CRP, C-reactive protein. 
Table 4. Univariate analyses on the risk for overall colorectal adenoma according to sex groups

\begin{tabular}{|c|c|c|c|c|c|c|c|c|}
\hline \multirow[b]{2}{*}{ Characteristic } & \multicolumn{2}{|c|}{ Men } & \multicolumn{5}{|c|}{ Women } & \multirow[b]{2}{*}{$\mathrm{p}$-values } \\
\hline & $\begin{array}{c}\text { No colorectal } \\
\text { adenoma } \\
(\mathrm{n}=1,019) \\
\end{array}$ & $\begin{array}{c}\text { Any colorectal } \\
\text { adenoma } \\
(\mathrm{n}=311)\end{array}$ & OR & $\mathrm{p}$-values & $\begin{array}{c}\text { No colorectal } \\
\text { adenoma } \\
(\mathrm{n}=498)\end{array}$ & $\begin{array}{l}\text { Any colorectal } \\
\text { adenoma } \\
(\mathrm{n}=74)\end{array}$ & OR & \\
\hline Alcohol consumer & $543(53.0)$ & $157(50.0)$ & $0.8(0.6-1.1)$ & 0.398 & $196(39.0)$ & $23(31.0)$ & $0.6(0.4-1.1)$ & 0.200 \\
\hline Smoking ( $\geq 20$ pack/yr) & $276(27.0)$ & $102(32.0)$ & $1.3(0.9-1.7)$ & 0.053 & $75(15.0)$ & $8(10.0)$ & $0.6(0.3-1.4)$ & 0.381 \\
\hline History of hypertension & $279(27.3)$ & $86(27.6)$ & $1.0(0.7-1.3)$ & 0.942 & $124(24.8)$ & $22(29.8)$ & $1.2(0.7-2.1)$ & 0.392 \\
\hline History of diabetes & $84(8.2)$ & $30(9.6)$ & $1.1(0.7-1.8)$ & 0.487 & $49(9.8)$ & $4(5.4)$ & $0.5(0.1-1.4)$ & 0.284 \\
\hline History of dyslipidemia & $85(8.3)$ & $24(7.7)$ & $0.9(0.5-1.4)$ & 0.814 & $45(9.0)$ & $5(6.7)$ & $0.7(0.2-1.9)$ & 0.661 \\
\hline History of CVA & $7(0.6)$ & $5(1.6)$ & $2.3(0.7-7.4)$ & 0.166 & $9(1.8)$ & $0(0)$ & $0.8(1.1-1.1)$ & 0.613 \\
\hline $\begin{array}{l}\text { History of angina or } \\
\text { myocardial infarction }\end{array}$ & $40(3.9)$ & $14(4.5)$ & $1.1(0.6-2.1)$ & 0.625 & $23(4.6)$ & $1(1.3)$ & $0.2(0.03-2.1)$ & 0.346 \\
\hline Regular exercise & $862(84.9)$ & $262(84.5)$ & $0.9(0.6-1.3)$ & 0.857 & $402(80.5)$ & $56(75.6)$ & $0.7(0.4-1.3)$ & 0.349 \\
\hline Metabolic syndrome & $261(25.6)$ & $93(29.9)$ & $1.2(0.9-1.6)$ & 0.143 & $46(9.2)$ & $7(9.4)$ & $1.0(0.4-2.3)$ & 1.000 \\
\hline Stool OB & $91(25.4)$ & $25(26.4)$ & $1.0(0.6-1.7)$ & 0.895 & $42(26.3)$ & $3(17.4)$ & $0.6(0.1-2.2)$ & 0.567 \\
\hline Arterial stiffness & $154(41.7)$ & $67(52.4)$ & $0.6(0.4-0.9)$ & 0.030 & $66(35.6)$ & $16(45.7)$ & $0.6(0.3-1.3)$ & 0.261 \\
\hline
\end{tabular}

Values are presented as number (\%).

OR, odds ratio; CVA, cerebral vascular accident; Stool OB, stool occult blood.

Table 5. Univariate analyses on the risk for overall colorectal adenoma according to sex groups (continuous variables)

\begin{tabular}{|c|c|c|c|c|c|c|}
\hline \multirow[b]{2}{*}{ Characteristic } & \multicolumn{2}{|c|}{ Men } & \multirow[b]{2}{*}{$p$-values } & \multicolumn{2}{|c|}{ Women } & \multirow[b]{2}{*}{$p$-values } \\
\hline & $\begin{array}{l}\text { No colorectal } \\
\text { adenoma } \\
(\mathrm{n}=1,019)\end{array}$ & $\begin{array}{l}\text { Any colorectal } \\
\text { adenoma } \\
(\mathrm{n}=311)\end{array}$ & & $\begin{array}{c}\text { No colorectal } \\
\text { adenoma } \\
(\mathrm{n}=498)\end{array}$ & $\begin{array}{l}\text { Any colorectal } \\
\text { adenoma } \\
(\mathrm{n}=74)\end{array}$ & \\
\hline Age (yr) & $47.3 \pm 6.3$ & $48.9 \pm 6.5$ & $<0.001$ & $47.9 \pm 7.1$ & $50.3 \pm 7.6$ & 0.015 \\
\hline Soft lean mass $(\mathrm{kg})$ & $52.5 \pm 5.5$ & $51.9 \pm 5.7$ & 0.186 & $36.5 \pm 4.1$ & $37.0 \pm 3.4$ & 0.445 \\
\hline Systolic blood pressure (mmHg) & $122.5 \pm 11.8$ & $123.8 \pm 11.6$ & 0.106 & $115.3 \pm 13.9$ & $117.1 \pm 13.5$ & 0.327 \\
\hline Diastolic blood pressure $(\mathrm{mmHg})$ & $76.4 \pm 9.7$ & $77.5 \pm 9.2$ & 0.103 & $69.7 \pm 93$ & $70.7 \pm 10.3$ & 0.424 \\
\hline $\mathrm{HbA1c}(\mathrm{mmol} / \mathrm{mol})$ & $5.7 \pm 0.8$ & $5.8 \pm 1.1$ & 0.051 & $5.5 \pm 0.7$ & $5.6 \pm 0.4$ & 0.787 \\
\hline Abdominal circumference $(\mathrm{cm})$ & $84.1 \pm 7.6$ & $83.7 \pm 7.3$ & 0.485 & $73.2 \pm 7.8$ & $75.8 \pm 8.1$ & 0.015 \\
\hline Triglycerides (mg/dL) & $157.8 \pm 102.3$ & $161.4 \pm 108.7$ & 0.636 & $100.2 \pm 71.8$ & $102.2 \pm 68.9$ & 0.817 \\
\hline Glucose (mg/dL) & $82.8 \pm 37.2$ & $86.5 \pm 40.3$ & 0.150 & $80.7 \pm 32.4$ & $84.0 \pm 26.9$ & 0.426 \\
\hline $\mathrm{HDL}(\mathrm{mg} / \mathrm{dL})$ & $45.2 \pm 10.4$ & $46.3 \pm 11.4$ & 0.161 & $54.6 \pm 12.1$ & $53.4 \pm 10.1$ & 0.446 \\
\hline CEA (ng/mL) & $1.4 \pm 1.0$ & $1.8 \pm 1.4$ & $<0.001$ & $1.0 \pm 0.7$ & $1.1 \pm 0.8$ & 0.177 \\
\hline NSE (ng/mL) & $7.0 \pm 3.2$ & $6.2 \pm 2.4$ & 0.131 & & & \\
\hline CA19-9 (ng/mL) & $7.6 \pm 6.8$ & $8.0 \pm 6.8$ & 0.424 & $9.8 \pm 8.8$ & $11.1 \pm 14.0$ & 0.351 \\
\hline CA125 (ng/mL) & & & & $16.5 \pm 22.3$ & $15.2 \pm 10.3$ & 0.657 \\
\hline PSA (ng/mL) & $1.0 \pm 0.7$ & $1.2 \pm 1.3$ & 0.036 & & & \\
\hline $\mathrm{AFP}(\mathrm{ng} / \mathrm{mL})$ & $3.2 \pm 2.0$ & $3.3 \pm 1.8$ & 0.583 & $2.9 \pm 1.8$ & $3.3 \pm 0.3$ & 0.316 \\
\hline $\mathrm{CRP}(\mathrm{mg} / \mathrm{L})$ & $0.2 \pm 1.0$ & $0.3 \pm 1.3$ & 0.460 & $0.1 \pm 0.5$ & $0.3 \pm 1.8$ & 0.522 \\
\hline
\end{tabular}

Values are presented as mean \pm standard deviation.

HDL, high-density lipoprotein; CEA, carcinoembryonic antigen; NSE, neuron-specific enolase; CA19-9, carbohydrate antigen 19-9; CA125, cancer antigen 125; PSA, prostate-specific antigen; AFP, alpha-feto-protein; CRP, C-reactive protein.

\section{Prevalence of colorectal adenoma in males aged 40-49 years with risk factors}

The prevalence of colorectal adenoma in young male sub- jects (40-49 years) was $22.4 \%(153 / 681)$. Among these subjects $(\mathrm{n}=153)$, the prevalence of colorectal adenoma was $44.8 \%$ $(13 / 29)$ in smokers with an elevated CEA level and 25.2\% (99/392) in non-smokers with an elevated CEA level. In sub- 
Table 6. Multivariate analyses on the risk for overall colorectal adenoma

\begin{tabular}{lcr}
\hline \multicolumn{1}{c}{ Variable } & $\begin{array}{c}\text { Adjusted OR } \\
(95 \% \mathrm{CI})\end{array}$ & $p$-values \\
\hline Sex & $2.3(1.2-4.6)$ & $<0.001$ \\
Smoking ( $\geq 20 \mathrm{pack} / \mathrm{yr})$ & $1.1(0.9-1.0)$ & 0.029 \\
Metabolic syndrome, n (\%) & $1.0(0.5-1.3)$ & 0.173 \\
Age, yr & $1.2(0.9-1.1)$ & 0.001 \\
Soft lean mass, n (\%) & $0.9(0.9-1.0)$ & 0.276 \\
Systolic blood pressure (mmHg) & $1.0(0.9-1.0)$ & 0.592 \\
Diastolic blood pressure (mmHg) & $1.0(0.9-1.0)$ & 0.437 \\
HbA1c (mmol/mol) & $0.9(0.7-1.1)$ & 0.822 \\
Abdominal circumference (cm) & $1.0(0.9-1.0)$ & 0.268 \\
CEA (ng/mL) & $1.1(0.9-1.3)$ & 0.024 \\
\hline
\end{tabular}

HbA1c, glycosylated hemoglobin; CEA, carcinoembryonic antigen.

Table 7. AUROC of CEA for colorectal adenoma in male under 50 years of age

\begin{tabular}{lcc}
\hline & $\begin{array}{c}\text { Non-smoking } \\
(\mathrm{n}=505)\end{array}$ & $\begin{array}{c}\text { Smoking } \\
(\mathrm{n}=376)\end{array}$ \\
\hline AUROC & 0.600 & 0.615 \\
& $(95 \%$ CI, 0.543-0.656) & $(95 \%$ CI, 0.540-0.690) \\
Cut off value of & 1.0 & 2.5 \\
high CEA (ng/mL) & & \\
Sensitivity (\%) & 76.8 & 70.9 \\
Specificity (\%) & 64.8 & 57.9 \\
\hline
\end{tabular}

AUROC, area under the receiver operating characteristic curve; $\mathrm{CI}$, confidence interval; CEA, carcinoembryonic antigen.

jects with a normal CEA level, the prevalence of colorectal adenoma was $15.4 \%(11 / 71)$ in smokers and $15.8 \%(30 / 189)$ in non-smokers. In contrast, the prevalence of colorectal adenoma in older female subjects ( $\geq 50$ years) was $17.5 \%(16 / 91)$.

\section{DISCUSSION}

In our study, we found that $23.3 \%$ of subjects in the male group and $12.9 \%$ of subjects in the female group had more than one colorectal adenoma. In addition, the prevalence of colorectal adenoma in subjects 40-49 years of age and in those $\geq 50$ years was $18.4 \%$ and $21.2 \%$, respectively. The prevalence of colorectal adenoma was higher in the young male 40-49 years age group (22.4\%) compared to the female 50-59 years age group (15.8\%). In addition, all advanced adenomas were found in males. Although the results of the present study correspond with those of earlier Korean studies [11,12,15], the prevalence of colorectal adenoma was lower than that in other studies. Recently, it was reported that the prevalence of colorectal adenoma in the male 40-49 years age group in Korea was much higher (26.1-27.9\%), compared with that in Western population $[9,10,16]$. The prevalence of colorectal adenoma in subjects aged 40-49 years including both males and females in Western countries is $12-15.3 \%$. However in our study, the prevalence of advanced adenoma in subjects aged 40-49 years (0.7\%) was much lower than that in Western population (1.5-3.5\%). It was suggested that earlier detection and prior removal of polyps during screening programs in Korea may reduce the occurrence of advanced adenoma and adenocarcinoma. In addition, participants with poor bowel preparation were excluded from this study.

In multivariate analysis, adenoma was significantly associated with male sex, age, and CEA level in this study. There are many studies that investigated the risk factors of colorectal adenocarcinoma and adenoma. It was reported that 9 risk factors (sex, age, first-degree relatives with a history of CRC, cigarette smoking, alcohol consumption, red meat consumption, regular intake of nonsteroidal anti-inflammatory drugs, previous colonoscopy, and previous detection of polyps) were significantly associated with risk of advanced neoplasms [17]. Another several studies showed that male gender, positive occult blood, positive serology of Helicobacter pylori, and hypertriglycemia [18].

Hyperhomocysteinemia [19] and a higher level of brachial ankle PWV [20] were associated risk factors of colorectal adenoma in our study, the metabolic syndrome was not significantly associated with colorectal adenoma in multivariate analysis. There are many studies that support the relationship between colorectal adenoma and metabolic syndrome. It was reported that the metabolic syndrome components, in particular obesity, will significantly improve the efficacy of individual CRC screening [21]. Increasing levels of glucose, Homeostatic Model Assessment values, levels of $\mathrm{HbA1c}$ and C-peptide, and metabolic syndrome are significantly associated with prevalence of adenomas [22-28]. However, another study reported that no statistically significant associations with adenomas were observed for the markers of the metabolic syndrome, with the exception of a strong positive association for use of diabetes medications [29]. A further study is needed.

The main use of CEA in CRC is for surveillance following 
treatment of primary cancer [30]. However, in this study, there was a significant relationship between colorectal adenoma and CEA level. In addition, the prevalence of colorectal adenoma in male subjects aged 40-49 years with elevated CEA level was much higher than that in woman subjects above 50 years. Measurement of CEA level is relatively inexpensive and causes minimal inconvenience to the patients. Hence, its application to high risk subjects should be considered.

It was reported that among 40-49 year-old patients undergoing screening colonoscopy because of first degree relatives with polyps, the prevalence of adenomas was greater than that in a control population [31] and it was similar to that observed in older subjects with the same CRC risk [32]. Rectal bleeding warrants colonoscopy to detect advanced neoplasia in those aged 40-49 years, whereas non-bleeding symptoms, including some traditionally regarded as "alarm" symptoms, were associated with a much lower risk for neoplasia compared with the risk in screening patients aged 50-54 years [33]. In another study performed in USA, the author also suggested that screening in men between 45 and 49 years of age may be cost-effective compared to screening between 50 and 54 years of age depending on societal willingness to pay [34]. Hence, we should consider another risk factor before we select the candidate for colorectal screening.

Our study has several strengths. First, our study included all risk factors of colorectal adenoma including regular exercise, smoking, and alcohol. This is more difficult to achieve in large-scale population-based screening programs. Thus, our data was suitable for analysis of risk factors of colorectal adenoma. Second, the CEA level was compared with prevalence of colorectal adenoma. It was significantly associated with non-advanced colorectal adenoma. Hence, the CEA level can be used to select the right candidate for CRC screening, Third, all participants received a complete colonoscopy. Thus, we can minimize the possibility of missing colorectal adenoma.

Our study has several limitations. First, it was a retrospective study. There is a possibility of selection bias toward health-conscious individuals in the enrolled population, which may limit the generalization of the findings to the general population. Second, a relatively small number of participants were enrolled in this study. However, the number of men aged 40-49 years was not so small. Thus, the study did not lack data for analysis of risk factors in young male subjects Third, a small number of advanced adenoma and adenocar- cinoma patients were included. As mentioned above, it is thought that we excluded the subjects with poor bowel preparation, and Korean CRC screening program can achieve early detection and removal.

In conclusion, male sex, smoking, and high CEA level seem to be associated with colorectal adenoma. High CEA level may be a diagnostic marker for any colorectal adenoma in Korean men aged 40-49 years. Further studies with a larger sample size are needed to confirm the exact role of CEA as a diagnostic marker of colorectal adenoma in Korean 40-49 years old. The prevalence of colorectal adenoma in Korean managed 40-49 years with risk factors was much higher than that in 50 year old women with average risk. Cost-effectiveness studies investigating the optimal age to start colonoscopy screening and etiological studies to identify the reasons for the increasing trend of colorectal adenomas in Koreans are needed.

\section{CONFLICT OF INTEREST}

The authors have no conflicts of interest to disclose.

\section{REFERENCES}

1. Ferlay J, Shin HR, Bray F, Forman D, Mathers C, Parkin DM. Estimates of worldwide burden of cancer in 2008: GLOBOCAN 2008. Int J Cancer 2010;127:2893-917.

2. Jung KW, Won YJ, Kong HJ, Oh CM, Lee DH, Lee JS. Cancer statistics in Korea: incidence, mortality, survival, and prevalence in 2011. Cancer Res Treat 2014;46:109-23.

3. Rex DK, Johnson DA, Anderson JC, Schoenfeld PS, Burke CA, Inadomi JM, et al. American College of Gastroenterology guidelines for colorectal cancer screening 2009 [corrected]. Am J Gastroenterol 2009;104:739-50.

4. Sung JJ, Ng SC, Chan FK, Chiu HM, Kim HS, Matsuda T, et al. An updated Asia Pacific Consensus Recommendations on colorectal cancer screening. Gut 2015;64:121-32.

5. Lee BI, Hong SP, Kim SE, Kim SH, Kim HS, Hong SN, et al. Korean guidelines for colorectal cancer screening and polyp detection. Clin Endosc 2012;45:25-43.

6. Nishihara R, Wu K, Lochhead P, Morikawa T, Liao X, Qian $\mathrm{ZR}$, et al. Long-term colorectal-cancer incidence and mortality after lower endoscopy. N Engl J Med 2013;369:1095-105.

7. Jung YS, Ryu S, Chang Y, Yun KE, Park JH, Kim H, et al. Risk factors for colorectal neoplasia in persons aged 30 to 39 years and 40 to 49 years. Gastrointest Endosc 2015;81: 637-45.e7.

8. Chang LC, Wu MS, Tu CH, Lee YC, Shun CT, Chiu HM. Metabolic syndrome and smoking may justify earlier colorectal cancer screening in men. Gastrointest Endosc 2014;79: 961-9. 
9. Rundle AG, Lebwohl B, Vogel R, Levine S, Neugut AI. Colonoscopic screening in average-risk individuals ages 40 to 49 vs 50 to 59 years. Gastroenterology 2008;134:1311-5.

10. Imperiale TF, Wagner DR, Lin CY, Larkin GN, Rogge JD, Ransohoff DF. Results of screening colonoscopy among persons 40 to 49 years of age. N Engl J Med 2002;346:1781-5.

11. Yang MH, Rampal S, Sung J, Choi YH, Son HJ, Lee JH, et al. The prevalence of colorectal adenomas in asymptomatic Korean men and women. Cancer Epidemiol Biomarkers Prev 2014;23:499-507.

12. Chung SJ, Kim YS, Yang SY, Song JH, Park MJ, Kim JS, et al. Prevalence and risk of colorectal adenoma in asymptomatic Koreans aged 40-49 years undergoing screening colonoscopy. J Gastroenterol Hepatol 2010;25:519-25.

13. Alberti KG, Eckel RH, Grundy SM, Zimmet PZ, Cleeman JI, Donato KA, et al. Harmonizing the metabolic syndrome: a joint interim statement of the International Diabetes Federation Task Force on Epidemiology and Prevention; National Heart, Lung, and Blood Institute; American Heart Association; World Heart Federation; International Atherosclerosis Society; and International Association for the Study of Obesity. Circulation 2009;120:1640-5.

14. Lee SY, Park HS, Kim DJ, Han JH, Kim SM, Cho GJ, et al. Appropriate waist circumference cutoff points for central obesity in Korean adults. Diabetes Res Clin Pract 2007;75: 72-80.

15. Kim HY, Kim SM, Seo JH, Park EH, Kim N, Lee DH. Age-specific prevalence of serrated lesions and their subtypes by screening colonoscopy: a retrospective study. BMC Gastroenterol 2014;14:82.

16. Ferlitsch M, Reinhart K, Pramhas S, Wiener C, Gal O, Bannert $\mathrm{C}$, et al. Sex-specific prevalence of adenomas, advanced adenomas, and colorectal cancer in individuals undergoing screening colonoscopy. JAMA 2011;306:1352-8.

17. Tao S, Hoffmeister M, Brenner H. Development and validation of a scoring system to identify individuals at high risk for advanced colorectal neoplasms who should undergo colonoscopy screening. Clin Gastroenterol Hepatol 2014;12:478-85.

18. Kim HS, Baik SJ, Kim KH, Oh CR, Lee SI. Prevalence and risk factors of colorectal adenoma in 14,932 Koreans undergoing screening colonoscopy. Korean J Gastroenterol 2013; 62:104-10. Korean.

19. Lim YJ, Kim JH, Park SK, Son HJ, Kim JJ, Kim YH. Hyperhomocysteinemia is a risk factor for colorectal adenoma in women. J Clin Biochem Nutr 2012;51:132-5.

20. Kim HB, Lee HR, Shim JY, Na HY, Park BJ, Jung DH, et al. The association between arterial stiffness and colorectal adenomatous polyp in women. J Womens Health (Larchmt) 2011;20:765-9.

21. Wang JY, Li ZT, Zhu YM, Wang WC, Ma Y, Liu YL. Utility of the Asia-Pacific colorectal screening scoring system and the presence of metabolic syndrome components in screening for sporadic colorectal cancer. World J Gastroenterol 2014; 20(32):11394-9.
22. Ishino K, Mutoh M, Totsuka Y, Nakagama H. Metabolic syndrome: a novel high-risk state for colorectal cancer. Cancer Lett 2013;334:56-61.

23. Rampal S, Yang MH, Sung J, Son HJ, Choi YH, Lee JH, et al. Association between markers of glucose metabolism and risk of colorectal adenoma. Gastroenterology 2014;147:7887.e3.

24. Sato T, Takeda H, Sasaki Y, Kawata S. Increased homeostasis model assessment-insulin resistance is a risk factor for colorectal adenoma in Japanese males. Tohoku J Exp Med 2011; 223:297-303.

25. Kim MC, Kim CS, Chung TH, Park HO, Yoo CI. Metabolic syndrome, lifestyle risk factors, and distal colon adenoma: a retrospective cohort study. World J Gastroenterol 2011; 17(35):4031-7.

26. Kim KS, Moon HJ, Choi CH, Baek EK, Lee SY, Cha BK, et al. The frequency and risk factors of colorectal adenoma in health-check-up subjects in south Korea: relationship to abdominal obesity and age. Gut Liver 2010;4:36-42.

27. Kang HW, Kim D, Kim HJ, Kim CH, Kim YS, Park MJ, et al. Visceral obesity and insulin resistance as risk factors for colorectal adenoma: a cross-sectional, case-control study. Am J Gastroenterol 2010;105:178-87.

28. Kim JH, Lim YJ, Kim YH, Sung IK, Shim SG, Oh SO, et al. Is metabolic syndrome a risk factor for colorectal adenoma? Cancer Epidemiol Biomarkers Prev 2007;16:1543-6.

29. Tsilidis KK, Brancati FL, Pollak MN, Rifai N, Clipp SL, Hoffman-Bolton J, et al. Metabolic syndrome components and colorectal adenoma in the CLUE II cohort. Cancer Causes Control 2010;21:1-10.

30. Gonzalez-Pons M, Cruz-Correa M. Colorectal cancer biomarkers: where are we now? Biomed Res Int 2015;2015: 149014.

31. Gupta A, Samadder J, Elliott E, Sethi S, Schoenfeld P. Prevalence of adenomas and advanced adenomas in patients in the 40- to 49-year age group undergoing screening colonoscopy because of a family history of adenoma/polyp in a first-degree relative. Gastrointest Endosc 2012;75:705-11.

32. Del Vecchio Blanco G, Cretella M, Paoluzi OA, Caruso A, Mannisi E, Servadei F, et al. Adenoma, advanced adenoma and colorectal cancer prevalence in asymptomatic 40- to 49year-old subjects with a first-degree family history of colorectal cancer. Colorectal Dis 2013;15:1093-9.

33. Cha JM, Kozarek RA, La Selva D, Gluck M, Ross A, Chiorean $\mathrm{M}$, et al. Findings of diagnostic colonoscopy in young adults versus findings of screening colonoscopy in patients aged 50 to 54 years: a comparative study stratified by symptom category. Gastrointest Endosc 2015;82:138-45.

34. Ness RM, Holmes AM, Klein R, Dittus R. Cost-utility of onetime colonoscopic screening for colorectal cancer at various ages. Am J Gastroenterol 2000;95:1800-11. 